\title{
Corrigendum
}

\section{Changes in outpatient antibiotic utilization, 2000-2016: More people are receiving fewer antibiotics — CORRIGENDUM}

In the above mentioned article by Cocoros et $\mathrm{al}^{1}$, the legend for figure 1 was incorrect due to an error introduced during typesetting. The correct figure 1 and legend appear below:

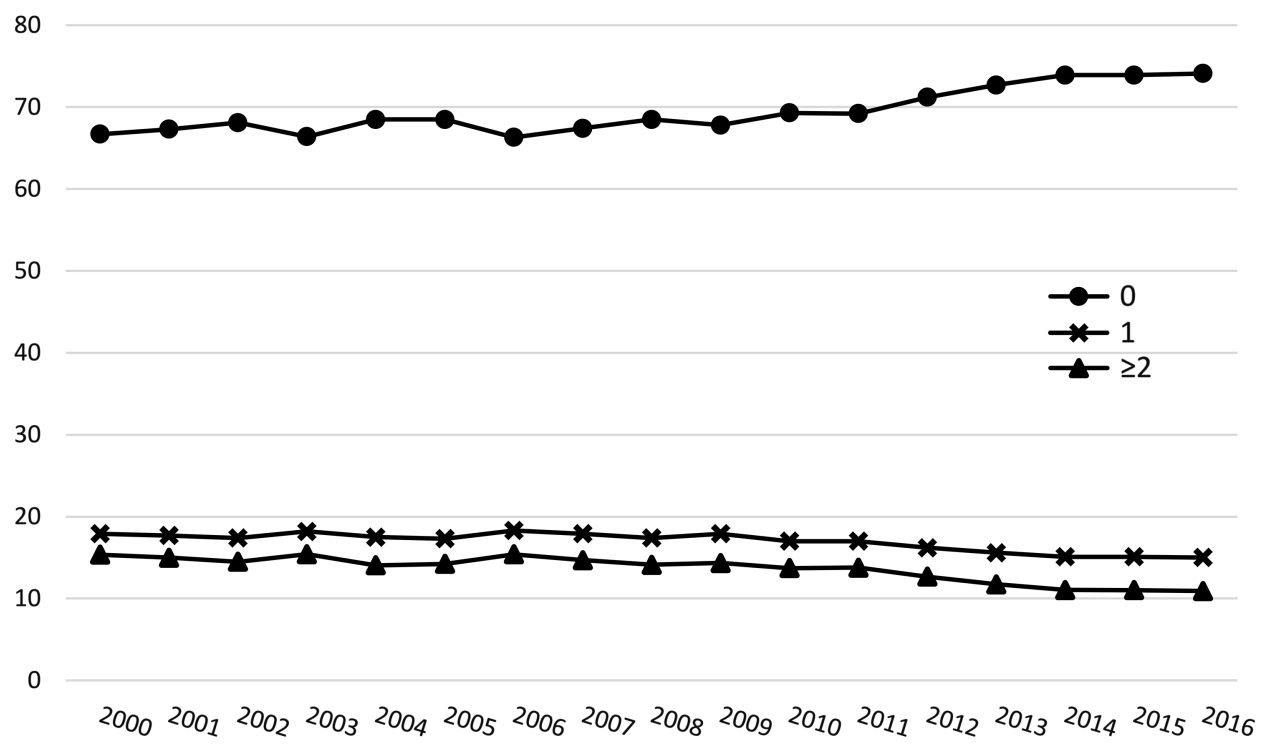

The publisher apologizes for the error.

\section{REFERENCE}

Cocoros NM, Ochoa A, Klompas M. Changes in outpatient antibiotic utilization, 2000-2016: More people are receiving fewer antibiotics. Infect Control Hosp Epidemiol 2019;40:372-374. 